\title{
Opportunities and Challenges in Ayurveda: Global Perspective
}

\section{Gundu HR Rao*}

Department of Medicine and Pathology Anesthesiology, Lillehei Heart Institute, Academic Health Center, University of Minnesota, USA

*Corresponding Author: Gundu HR Rao, Emeritus Professor, Laboratory Medicine and Pathology Anesthesiology, Lillehei Heart Institute, University of Minnesota, USA. Tel: 301444 4545; E-mail: gundurao9@gmail.com

Received date: May 31, 2017; Accepted date: June 09, 2017; Published date: June 19, 2017

Copyright: (c) 2017 Rao GHR. This is an open-access article distributed under the terms of the Creative Commons Attribution License, which permits unrestricted use, distribution, and reproduction in any medium, provided the original author and source are credited.

\section{Commentary}

I participated in the $7^{\text {th }}$ World Ayurveda Conference (WAC) in Kolkata a few weeks ago, at the invitation of Dr. Geetha Krishanan, Secretary WAC-2016. As an outsider, I enjoyed the meetings, the exposition and the opportunity to meet experts in various fields of Traditional Medicine. I was frequently asked during the conference, whether I was a Vaidya or a traditional heath provider or promoter? As I explained to the experts who asked me this question, I feel that it is essential for me to provide some introductory explanations, as to why I am interested in Traditional Indian Medicine. I am the founder and CEO of a professional society; South Asian Society on Atherosclerosis and Thrombosis (SASAT). I have been organizing international conference on Atherosclerosis and Thrombosis for over three decades in India. We have published several books on this subject in India [1-6]. During our conference in 2006 (www.sasat.org/ 7_symp_prog_13.htm). We organized a round table discussion on, "The need for integration of Indian Traditional Medicine for the development of affordable healthcare in India". Since then, we are working on this idea, so that we can develop a comprehensive seamless Integrated Healthcare for India.

During SASAT-2010 conference in Bangalore, we organized a Round Table Discussion on the subject of "How to Provide Affordable Health Care to All". The experts who were present in these discussions, including Director AYUSH, Karnataka, felt an immediate need for the creation of a novel platform that provides accessible, acceptable and affordable health care for all. Since the modern medicine as we know today, cannot be provided to all levels of the community, it was felt desirable to bring all the Indian traditional therapies on a common platform. In view of these observations, it was decided to launch a platform called, Global Alliance of Traditional Health Systems (GATHS:www.GATHS.org), to standardize and promote traditional therapies. We also launched a sister platform called, Mind Body Spirit Society of India, to complement the Integrative Medicine.

The integrative approach emphasizes prevention, health maintenance and early intervention, and utilizes all appropriate, evidenced-based and personalized therapeutic approaches, to achieve optimal health and wellbeing across one's lifespan. Although, this is the basic strategy of all Indian traditional health systems, they lack evidence-based or observation-based clinical data, to support the benefits of such an approach. This concept was presented at the $4^{\text {th }}$ World Ayurveda Conference (December 2010) in Bangalore. I also presented our collective views on this subject at the World Ayurveda Conference in Bhopal. Currently, we have put together a consortium of experts, to develop an affordable healthcare platform at the Dayananda Sagar Institutions (DSI), Bangalore, India. We are planning to organize an international workshop on this topic in February of 2017 in Bengaluru.
During the WAC-2016 meetings, one evening, I had the opportunity to have dinner with Prof Vijay Bhatkar, the National President of Vijnana Bharathi, and the premier science professional association of India and the architect of Indian Super-computer. During my conversation with him, I mentioned our interest in developing an ITsupported, Cloud-enabled affordable health care system. He inquired whether I was really serious about developing such a platform? My answer was affirmative. He expressed his interest to encourage us in this effort and at the same time asked me, if I would publish an article on the topic of "Opportunities and Challenges in Ayurveda; a Global Perspective". In view of our interest in the development of Integrative Health, I attended all the plenary lectures during the WAC-2016, to feel the pulse and views of various experts. What I am going to present in this overview is collective thoughts of the various experts and my own interpretations and opinions.

The Department of Ayurveda, Yoga and Naturopathy, Unani, Siddha and Homoeopathy, abbreviated as AYSH, is a governmental body in India, purposed with developing, education and research in Ayurveda (Indian Traditional Medicine), Yoga, Naturopathy, Unani, Siddha, Homeopathy, Sowa-rigpa (Traditional Tibetan Medicine) and other related indigenous Medicine Systems (Wikipedia). The Platform was started in 1995 under the Department of Indian Systems of Medicine. It received its current name AYUSH in 2003 and the Ministry of Ayush was formed in 2014. Both the Secretary of AYUSH as well as Minister of State for Ministry of AYUSH spoke at the plenary meetings. The Director of National Institute for Ayurveda (NIA), Jaipur, India, also addressed the gathering of experts. As an observer who has participated in earlier meetings of WAC, I was pleasantly surprised by the changed attitude of the leaders in this field. In the $4^{\text {th }}$ WAC in Bangalore, I found an attitude of defiance, lack of confidence, blind faith of acceptance, without any evidence to support the claims, and a certain degree of reliance on the "age" of this ancient science of healing. On the other hand, during this conference, from the Minister of State, Hon. Sri Shripad Y. Naik to the Secretary of AYUSH Mr. Ajith Sharanji and the Director of NIA, Prof. Sanjiv Sharma, I could see a change of attitude which was positive, optimistic and encouraging.

Just to give you an example, in 2006, I had approached AYUSH secretariat to develop a joint program with the Consortium of Academies for Complimentary and Alternate Medicine (CAM), USA. I had approached AYUSH to develop a bilateral program with this group so that we can increase our credibility and visibility. We were to send delegates from India to their annual meetings at Oregon. I was not able to get any cooperation from AYUSH, New Delhi. Furthermore, I was told by senior staff, that they did not need any recognition from the US as they already were recognized for centuries in India. To my pleasant surprise, during $7^{\text {th }}$ WAC meetings I found that there was quite a bit of enthusiasm to take Ayurveda to Global Platform. 
Page 2 of 5

Indeed, during the Valedictory program, we were made to take a pledge to make all-out efforts to promote Ayurveda in every possible way. Having taken such a pledge, all of us have to think as to how we will accomplish this goal? Newly elected US Presidential nominee, made it to the White house with a simple call, "Make America Great". We have heard similar calls in India about "Make in India", "Made in India", Make Mahan Bharat etc. Pledges and slogans are easy to make, but to develop the needed infrastructure, human resources, and improvements in educational standards, development of research and development in the field of Traditional Indian Medicine is not an easy task.

I will try to discuss in the next few paragraphs opportunities and challenges in this area. These ideas are not just my thoughts, but collective thoughts expressed by the experts during these extraordinary meetings. There are over 300 Ayurveda Colleges in India. There are relatively small numbers of colleges that offer $\mathrm{MD}, \mathrm{MS}$ or $\mathrm{PhD}$ in this field. In spite of the fact that there are as many qualified Vaidyas as allopathic doctors $(700,000)$, opportunities for these Vaidyas are limited. First and the foremost task for us is to find ways and means to provide these Vaidyas opportunities to improve their training, clinical skills, research capabilities and more than anything to develop confidence in their respective professional areas. Serious thoughts should be given to this issue. You cannot improve their status overnight as Madhya Pradesh Government did recently, by passing a bill providing legal status for them to practice modern medicine. It will only lower the standard of care in the State, not give the confidence or competence that they need, to compete in real life. This is like AYUSH asking the Global regulatory agencies, to lower their standard for approval, so that AYUSH products can get approval for Global market. We need to work on every possible way to improve Ayurveda education at all the accredited colleges, provide post graduate courses at every college, create interest in research and development of AYUSH products, establish standards for nomenclature of Ayurvedic terminologies, develop collaboration with Global organizations interested in CAM therapies, establish standard operating procedures (SOPs) develop cGMP facilities and methodologies for product development. These efforts need lot of funds, political will to implement and more than anything great leadership. We were told during the meeting that the annual budget of AYUSH is just about 1100 Crore rupees. If we want to bring this ancient art of healing to the same level or better than modern medicine, we need to muster the funds, political will and leadership to accomplish these goals.

Modern medicine has failed miserably in developing robust preventive medicine. Modern medicine is disease centric. Bulk of the investment is spent for the diagnosis of the risk and management of risk and interventions. Just a few recent examples, will reveal to us the importance of preventive medicine. As part of the 2020 impact goals, the American Heart Association (AHA) has set out seven ideal health goals; not smoking, maintaining normal weight, increased physical activity, a healthy diet, normal blood lipid levels, normal blood pressure and a normal fasting glucose. An analysis of the US National Health and Nutritional Examination Survey (NHANES) showed, that individuals who met five of the seven ideal metrics of AHA, had a 78\% reduction in the hazard ratio for all cause-mortality [7-10]. From the INTERHEART study, which included 52 countries, it is estimated that modifiable risk factors account for $90 \%$ of the population attributable risk for heart disease in Men and 94\% of the risk in Women [11]. As is the case with majority of clinical trials, the INTERHEART studies looked at the modifiable risk factors in developing the prevention strategies. However, a recent article by Khera et al., in New Engl J Med. showed, that in four studies with over 55,000 participants, a favorable lifestyle intervention was associated with nearly $50 \%$ lower relative risk for coronary artery disease, in spite of the genetic risk [12]. In a recent UK study, with over half million subjects providing the baseline data, researchers showed that incorporation of increased levels of physical activity as part of the commute to work, could reduce obesity among middle-aged adults in the UK.

In view of the fact that lifestyle changes, diet and exercise alone could reduce metabolic disease burden, the Traditional Medicine, which emphasizes these aspects in their practice can play a very important role. State of California, in USA has introduced Yoga in schools as way of lifestyle modification. They also have introduced mindfulness as a part of school curriculum in many schools. Prevention strategies should be employed at the earliest stages of human development, so that these practice become a way of life. For instance, when we discuss metabolic diseases, we think that earliest stage of intervention should be at the conception stage. I was the lead speaker for the session on metabolic diseases at the recent WAC meeting. Thirty percent of the children born in India are of low birth weight. These children develop metabolic diseases. We need to develop robust program for maternal and neonatal nutrition. We also need to develop a robust educational program to improve their nutrition at the time of conception and during their child bearing ages. Another area where we need intervention is in rehabilitation of post ischemic disease related events and stroke. Traditional therapies can play a very important role in developing robust preventive medicine programs to complement interventional therapies. National Institutes of Health (USA), has a dedicated institute (National Centre for Complementary and Integrated Health) with an annual budget of over USD150 million for supporting complimentary and alternate (CAM) medicine programs (https://nccih.nih.gov).

Now that I have expressed my views on the subject, let us examine what the experts on this subject say? The Secretary of AYUSH, told us during the WAC meetings that $85 \%$ of the herbs are collected from the wild. In view of this fact, availability of quality products is fragmented and not transparent. Some States in India have provided incentives to grow medicinal plants in ideal conditions so that quality and availability can be assured. Since this is such an important part of the Ayurvedic practice, private and public sectors should come together and establish cooperatives, develop certification process so that the quality as well as the remuneration to the growers of herbs is assured. According to the Secretary of AYUSH, the development in this field (Ayurveda) stopped several centuries ago. We are living on a system that has not seen any improvements in the modern days. As such, the practitioners have lost all confidence in the system. Their knowledge base should be improved to catch with the modern times and they should be encouraged to improve their knowledge on the health care beyond what is taught in the colleges. For instance, one of the Ayurvedic experts who were talking about hypertension mentioned that not much is known about the causative mechanisms for this condition. He need not limit his knowledge to just Ayurvedic texts. Abundant of literature exists on this topic. Learning about mechanisms of diseases need not be restricted to ancient texts alone. There should be no boundary when it comes to knowledge acquisition. Although there is considerable interest in the last few decades worldwide for Yoga and Ayurveda, these specialties are considered and promoted more or less as wellness therapies or at the most preventive therapies.

He also dealt in great length about the need for digitization, and recoding case studies. He was concerned about the fact that the articles 
Page 3 of 5

published in the Ayurvedic journals were not recognized as much, as those published in modern medical journals. He emphasized the need to come "out of the box", and create credibility and visibility for this discipline. He suggested development of treatment facilities rather than wellness platforms. He wondered as to why there are hardly any patients in teaching schools (320 Ayurvedic Colleges). How do students learn if there are no patients? One way to improve the standard of teaching and training future Vaidyas is to introduce accreditation $(\mathrm{NABH})$ system for the Traditional Health Colleges. Professor Sanjiv Sharma of National Institute for Ayurveda, Jaipur, spoke of the merits of Ayurveda as a holistic medicine and person centered medicine. He also acknowledged the fact that present day medicine is science-based, evidence-based and at the Global level expects all health care to be competitive and evidence-based. He was forthright in saying that Ayurvedic practitioners should come out of complacency, being defensive and accept the facts and the needs of the present times. He acknowledged that collecting evidence for Ayurvedic treatments may vary from the way clinical trials or done with allopathic medicine. However, he emphasized the need to develop appropriate models and demonstrate sufficient scientific evidence for the various therapies of this ancient system.

Professor Ram Vishwakarma of Institute of Integrative Medicine, Jammu, spoke of phytopharmaceuticals; "a bane or window of opportunity". He acknowledged that traditional Chinese system has done better than the Indian Traditional System. In China for instance, 350,000 staff work in more than 2500 hospitals of Traditional Medicine. Ninety percent of General Hospitals in China have Traditional Medicine and $50 \%$ of rural doctors are able to provide both traditional and allopathic medicine. 257,000 graduates from Traditional Universities have knowledge of both traditional and allopathic medicine. Over 83,000 pharmacists who are specialists in herbal medicine have graduated from Traditional Medicine Universities. Eight hundred manufacturing facilities generate an annual income of over 1800 million US Dollars. 340,000 farmers cultivate medicinal plants in China. He also discussed in length, as to how one could develop Ayurvedic drugs, and therapies like modern medicine. He also explained as to how the US has developed regulation for newer therapies such as for Botanicals, Biologics, Cellular and Molecular therapies. He told about the new drug development initiatives in China and lack of such initiatives in India, in spite of the fact the Government of India has encouraged development of phytopharmaceuticals. He mentioned about the fact, that Government of India Food and Safety Standards Authority of India (FSSAI) has guidelines for 400 Botanical plants that could be used for developing functional foods or nutritional supplements.

India has over 500 teaching Hospitals, 700,000 Vaidyas and thousands of dispensaries. Ministry for AYUSH is trying to get World Health Organization (WHO) recognition for these facilities. Every year 30,000 Vaidyas are added to this pool. Global market size for herbal products exceeds 5000 billion, whereas Indian share of this market is just under $0.9 \%$ According to the experts the infrastructure at these AYUSH facilities are poor. In May of 2015, Ayurveda got a nod from the Swiss Government. Practitioners of Indian Traditional Medicine, Ayurveda will soon be able to get a federally approved diploma after passing an examination. The authorities in Switzerland hope that this will be bring credibility, especially in the eyes of the insurance providers. The first exams are to be held in November and applicants have to first pass a series of six pre-exams. Although these examinations are open to foreign nationals, it will be offered only in German, French and Italian.
Dr. Dinesh C. Katoch, the adviser to AYUSH and to the Ministry of AYUSH, Government of India, spoke about the Government Policies, Strategies and Initiatives. He was upbeat on the immense potential for manufacturing trade of AYUSH products. He noted that there were just 45 manufacturing units run by Government of India compared to over 9000 by the private sector. He stressed the need to integrate AYUSH in healthcare delivery and National health programs. He also expressed the need for evidence-based applications and research by AYUSH practitioners. He suggested four key strategies to achieve the improvements needed by all AYUSH supported platforms:

1. Standardization of quality control (R \& D);

2. Sustainable development of resources;

3. Integration of AYUSH in health delivery systems;

4. Promotion of science and technology as integral part of AYUSH development for the deployment of AYUSH-based healthy living. As a part of this effort, to develop international cooperation.

He noted that steps for quality control should include compliance to GMP and Pharmacopoeia. Licensing requirements should require proof of safety and efficacy. They also should follow GCP guidelines published for clinical trials of AYUSH products. Finally, he summarized some "loose ends" that need immediate attention by the policy makers; 1) Weak compliance and enforcement of legal provisions; 2) Inadequate objective evidence of quality, safety and efficacy of products; 3) Lack of interest for manufacturing and R \& D of classical formulations; 4) Negligible use of scientific technologies for manufacturing; 5) AYUSH medical products by and large are not traded as medicines; 6) Veracity of misleading advertisements and rampant exaggerated claims. All of these "loose ends" need close examination so that appropriate strategies and action plans can be developed to strengthen the development of Integrated Healthcare platform that meets global standards.

Now that I have presented my views and the views of some of the leading speakers at the 7th WAC, at Kolkata, I would like to summarize the collective views so that the policy makers and the entire Indian Traditional Medicine promoters can use this information for further discussions, planning and implementation. In view of the fact that all of us who were present at the WAC conference took a pledge to promote these traditional Medical Systems to the best of our abilities, we should make an immediate effort to put together a consortium of experts of like-minded individuals, to pursue and promote these objectives. Four out of ten individuals use some form of alternate therapies in the USA. Hence, in the USA an Academic Consortium for Complementary and Alternative Medicine as well as Consortium of Academic Health Centres for Integrative Medicine have been established. I tried to find out who are the prominent Ayurveda specialists in India by an Internet search and failed to find the names of significant number of individuals, with national and international reputation. Hence just as an example, will name a few individuals that I know in this field; Dr. Shripad Naik, Dr. Ajit Sharanji, Prof Sanjiv Sharma, Dr. Vijay Bhatkar, Dr. Geetha Krishnan, Dr. Bhushan Patwardhan, Dr. Drashan Shankar, Dr. B.N. Gangadhar, Dr. Dinesh Katoch, Dr Ranjit Puranik, Dr Pratap Chauhan and Dr. H.R. Nagendra. Of course, the organizers of the WAC will have access to the names of other experts in this area and they should make an all-out effort, to recruit those who would bring strength to this consortium.

In one of the presentations, it was mentioned that phytochemicals or not included in the Ayurvedic Medicine category as they are the basis for allopathy. This just absurd. Phytochemicals are derived from 
Page 4 of 5

natural plants which do not belong exclusively to anyone. Manufacturers of Ayurvedic products certainly can use this natural resource to develop useful combinations and formulations. Chinese researchers have developed hundreds of phytochemicals or herbal products for global platform. In fact, if you look at the website of Sigma Aldrich, you will find hundreds of herbal products from Chinese Traditional Medicine listed for marketing. On the same site, if you search for products from Traditional Indian Medicine, you just get 10 references of articles on this subject. Prof. Ram Vishwakarma of Institute for Integrative Medicine, Jammu, in his presentation emphasized the window of opportunity we have to develop Ayurvedic drugs for use in Modern Medicine. We should encourage in every possible way the development of indigenous drugs from herbal source to the same standard as that is required for Modern Medicine. Ayush already has classification of AYUSH drugs depending upon the quality of products; Ayush Standard Mark and Ayush Premium Mark (WHOGMP/COPP, GMP/USFDA compliance).

There is no "Alternate Medicine", the editors of Journal of the American Medical Association (JAMA) wrote some time ago [11-13]. There is only scientifically proven evidence-based medicine supported by solid data or unproven medicine, for which scientific evidence is lacking. Similar views are expressed in the Editorial of New England J. Medicine $[13,14]$. Totally negative views were expressed by Prof Edzard Ernst of UK, the world's first professor of complementary medicine in the May issue (2011) of The Economist [15]. In spite of such negative criticisms by the experts, in various professional society journals as well as reputed international news weekly, the prestigious National Institutes of Health USA has increased the funding for the National Centre for Complementary and Integrative Health. https:// nccih.nih.gov. They have funded several research projects and created special research sites at various reputed US Academic Institutions [16].

In Columbia University, Dr. Fredi Kronenberg and her colleagues recognize the challenge (Rosenthal Centre for Complementary and Alternative Medicine), but do not back down from it. "What's been exciting at the centre," she says, "is that we bring them together; we put the methodologists, study design people, and biostatisticians in the same room with the Chinese practitioner and the Ayurvedic practitioner and the taichi practitioner and say, 'How can we study what it is that you do with a rigorous scientific design? Researchers, policy makers, Ayush administrators, Director of NIA should try to establish collaborative projects with US universities as well as with the staff of NCCIH. I did discuss the need to establish collaboration with this Institute with Dr Geetha Krishnan, Secretary, WAC. Prestigious Mayo Clinic of Rochester, Minnesota, has this to say about complementary and alternate medicine: Complementary and alternative medicine has never been more popular. Nearly 40 percent of adults report using complementary and alternative medicine, also called CAM for short. Doctors are embracing CAM therapies, too, often combining them with mainstream medical therapies-spawning the term "integrative medicine." We should take advantage of this increased popularity world-wide and initiate collaborative studies with reputed Institutions, Hospitals and Clinics to create credibility and visibility.

Clinical trials of Ayurvedic drugs, formulations and therapies are absolutely essential to convince international community about efficacy and safety of Ayurvedic practices [17]. One finds numerous claims about Ayurvedic medicine. A rational mind as well as researchers find it difficult to accept these claims, without robust scientific evidence. An announcement in Times of India, in August of
2102 says, "Mandatory clinical trials of herbal drugs soon". This is a welcome announcement. But the big question is, who will do it and where do you find funds to finance such studies? Department of AYUSH has come up with GCP guidelines for Ayurvedic medicine development [18]. Manufacturers of Ayurvedic drugs do not want to conduct such studies because of high cost involved. Therefore, there is a great dearth in the country for clinical trials organizations (CROs) for conducting clinical trials of Ayurvedic preparations. Dr. Ashok Vaidya suggests "reverse pharmacology" approach. In this approach, the medicines (Ayurvedic) which work in clinics are tested in the laboratory instead of classical pharmacology approach, where drugs are first tested in the laboratory [19].

Since there is a great concern and renewed interest in proving the efficacy and safety of Ayurvedic formulations, a consortium of experts should develop a "white paper" on the subject. They should provide standard protocols; help develop a few "National" level cGLP/cGMP testing facilities. An alternate suggestion will be to help develop a digitized data collection system that can be deployed at all the teaching hospitals and major Ayurvedic treatment facilities, to collect comprehensive information on their case reports. Dr Murty a delegate from USA informed the audience during the WAC, that he indeed he has developed a cloud-based first of a kind software exclusively for the AYURVEDA practitioners, called "Ayurmegha" (http:// www.drcloudemr.com/about). One can use such cloud-based electronic health record management system in all the teaching colleges, dispensaries, clinics and research establishments for standardized data collection. It has extensive clinical decision support system as well as standard formats for data collection, collation and review. Using such cloud- based health record systems; one can generate information on the types of diseases treated, efficacy and safety of the formulations tested, and the outcome of such treatments. This would be a first of a kind data collection effort for a Traditional Medicine System, where people have failed to come up with or agree on an acceptable clinical trial model for solid data acquisition.

In conclusion, I can say with confidence, that I could see a sense of pride in the lead speakers of the WAC conference in Kolkata. It was refreshing to see great enthusiasm to develop international collaborations. Participation from the foreign delegates (USA, UK, Switzerland, Germany, Italy and Argentina) and their enthusiasm to champion the cause of Indian Traditional Medicine in their respective countries was an indication of the growing interest in alternative, integrative therapies. Dr. Bhushan Patwardhan a great champion of Ayurveda, in his editorial writes that Ministry of AYUSH and the University Grants Commission (UGC) have issued advisory to all the Indian Universities to include AYUSH disciplines in their $\mathrm{PhD}$ programs. He further states that, to support these initiatives the Ministry has decided to offer 200 Senior Research Fellowships every year, for pursuing translational science research on AYUSH disciplines through National Eligibility Test (AYUSH-NET). He also notes that there is strengthened relationship between AYUSH and Indian Council of Medical Research (ICMR). I had the pleasure of meeting the Director General ICMR and discussing areas of mutual interest during the 7th WAC conference at Kolkata. As mentioned earlier in this article I have noticed considerable change in the attitude and perception of AYUSH practitioners. As mentioned by Prof. Ram Vishwakarma there is a window of opportunity to develop ASU drugs to the global market. We also notice similar expression of optimistic views in the very many editorials and articles written by B. Patwardhan and others in the Journal of Ayurveda and Integrative Medicine [20-23]. 
Citation: Rao GHR (2017) Opportunities and Challenges in Ayurveda: Global Perspective. Altern Integr Med 6: 239. doi: $10.4172 / 2327-5162.1000239$

Page 5 of 5

\section{References}

1. Rao GHR (1999) Hand Book of Platelet Physiology and Pharmacology. Kluwer Academic Publications. USA.

2. Rao GHR, Kakkar VV (2001) Coronary artery disease in South Asians: Epidemiology, risk factors, and prevention. JP Medical Publishers, India.

3. Rao GHR, Thanikachalam S (2005) Coronary artery disease: Risk promoters, pathophysiology and prevention. JP Medical Publishers, India.

4. Rao GHR, Eastlund T, Jagannathan, L (2005) Handbook of blood banking and transfusion medicine. JP Medical Publishers, India.

5. Rao GHR, Mohan V (2007) Type-2 diabetes in South Asians Epidemiology, risk factors and prevention. JP Medical Publishers, New Delhi, India.

6. Rao GHR (2014) Clinical handbook for the management of venous thrombosis and thromboembolic disorders.

7. Rao GHR, M Reddy (2015) Handbook on biotechnology, bioengineering and biomedical applications. Institution of Engineers, National Design Research Foundation, Bangalore, India.

8. Rao GHR (2016) Handbook on coronary artery disease. MacMillan Medical Communications, New Delhi, India.

9. Rao GHR (2017) Morphology, physiology and pharmacology of blood platelets. JP Medical Publishers, New Delhi, India.

10. Jones L, Hong Y, Labarthe D (2010) American Association Strategic Task Force and Statistics Committee. Defining and Setting National Goals for Cardiovascular health promotion and disease reduction. The American Heart Association Strategic and Impact Goal Through 2020 and beyond. Circ.

11. Yusuf D, Harker S, Ounpuu S, Dans T, Avezum A, et al. (2004) Inter heart study investigation. Effect of potentially modifiable risk factors associated with myocardial infarction in 52 countries (The Interheart Study) Case Control Study. Lancet 364: 937-952.

12. Khera AV, Emdin CA, Drake I, Natarajan P, Bick AG, et al. (2016) Genetic risk, adherence healthy lifestyle single and relative risk for coronary artery disease. $\mathrm{N}$ Engl J. Med 375: 2349-2358.

13. Fontanarosa PB, Lundberg GD (1998) Alternative medicine meets science. JAMA 280: 1618-1619.

14. Angell M, Kassirer JP (1998) Alternative medicine--the risks of untested and unregulated remedies. N Engl J Med 339: 839-841.

15. Ernst E: Thank yourself; there is no alternate medicine: virtually all alternate medicine is bunk. The Economist May 19th 2011.

16. NCCIH (2015) FY 2015 New and Competing Awards.

17. Sam P (2012) Create solid clinical trial data to convince international community about efficacy of Ayurveda. Pharmabiz.

18. GCP guidelines for ASU Drugs: http://www.Indianmedicine.in/ writeaddata/mainlineFile/File660.pdf

19. Raut A, Tillu G, Vaidya AB (2016) Reverse pharmacology effectuated by studies of Ayurvedic products for arthritis. Curr. Sci. 111: 337.

20. Patwardhan B (2016) Ayurvedic drugs in case: Claims, evidence, regulations and ethics. J Ayurveda Integr Med 7: 135-137.

21. Patwardhan B (2016) Integrity of Ayurveda. J Ayurveda Integr Med.7: 189-190.

22. Rao GHR, Gandhi PG (2014) Integrative medicine: Global Perspective. J Homeop Ayurv Med 3:150.

23. Rao GH (2015) Integrative approach to health: Challenges and opportunities. J Ayurveda Integr Med 6: 215-219. 